\title{
Genetic Diversity Assessment through Cluster and Principal Component Analysis in Potato (Solanum tuberosum L.) Genotypes for Processing Traits
}

\author{
Ebrahim Seid $^{1, *}$, Wassu Mohammed ${ }^{2}$, Tesfaye Abebe ${ }^{1}$ \\ ${ }^{1}$ Ethiopia Institute of Agricultural Research (EIAR), Holetta Agricultural Research Centre (HARC), P.O. Box: 2003, Addis Ab- \\ aba, Ethiopia. \\ ${ }^{2}$ Haramaya University, P.O. Box 138, Dire Dawa, Ethiopia.
}

How to cite this paper: Ebrahim Seid, Wassu Mohammed, Tesfaye Abebe. (2021) Genetic Diversity Assessment through Cluster and Principal Component Analysis in Potato (Solanum tuberosum L.) Genotypes for Processing Traits. International Journal of Food Science and Agriculture, 5(3), 440-447.

DOI: 10.26855/ijfsa.2021.09.014

Received: June 28, 2021

Accepted: July 23, 2021

Published: August 16, 2021

*Corresponding author: Ebrahim Seid, Ethiopia Institute of Agricultural Research (EIAR), Holetta Agricultural Research Centre (HARC), P.O. Box: 2003, Addis Ababa, Ethiopia.

Email: ibrahussen32@gmail.com

\begin{abstract}
Potato (Solanum tuberosum L.) is the third most important food crop in the world in terms of consumption after rice and wheat. It can be used as fresh products and commercially processed foods such as French fries and chips. In Ethiopia, the released varieties have not met the consumers' demand for processing purpose. Therefore, the objective of this study was to estimate the magnitude of genetic distance and to identify the major traits contributing for processing quality traits among the studied genotypes by using cluster and principal component analysis. The experiment was conducted during the main rainy season of 2017 at Holetta, Ethiopia. A total of 24 potato genotypes were evaluated for 23 quantitative traits in randomized complete block design with three replications. The genetic distances among the 24 potato genotypes ranged from 2.73 to 10.94 and the genotypes were grouped into six clusters based on quantitative traits. Cluster II consisted of $33.33 \%$, Cluster I contained $29.17 \%$, cluster III had $16.67 \%$ and cluster IV had $12.50 \%$ potato genotypes, while cluster V and VI contained each one (4.17\%) genotype. The first six principal components accounted for $88.20 \%$ for the observed variations among 24 potato genotypes. Of these, the first, the second and the third principal components constituted $34.30 \%, 20.70 \%$ and $12.00 \%$ of the variation, respectively. In conclusion, according to cluster mean and principal component analysis cluster II and cluster VI contained the best genotypes for highest total tuber yield, marketable tuber yield, specific gravity of tuber, dry matter content and total starch content traits and could be used as parents in crossing program targeted at developing processing type varieties.
\end{abstract}

\section{Keywords}

Genetic Diversity, Clustering, Dendrograms, Genotypes, Quantitative Traits and Tuber Quality

\section{Introduction}

Potato (Solanum tuberosum L.) is the third most important food crop in the world in terms of consumption after rice and wheat [1, 2]. The cultivated potatoes Solanum tuberosum are tetraploid $(2 \mathrm{n}=4 \mathrm{x}=48)$, while the native are highly diverse, diploids $(2 n=2 x=24)$, triploids $(2 n=3 x=36)$, tetraploids $(2 n=4 x=48)$, pentaploids $(2 n=5 x=60)$ and hexaploids $(2 n=6 x=72)$ [3]. The presence of genetically diverse and variable genotypes is vital for a successful breeding program. Information on genetic diversity among elite germplasm is essential for identifying promising lines for trait of interest and estimating genetic distinctness among parents [4]. Genetic diversity aids in the identification of suitable parents which is an essential step in breeding to develop new and improved cultivars with desirable characteristics, which in- 
clude both farmer-preferred traits (high yield potential, large seed, etc.) and breeder-preferred traits (pest and disease resistance and photosensitivity, etc.). Genetic diversity facilitates breeders to develop varieties for specific traits like quality improvement and tolerance to biotic and abiotic stresses [5]. Genetic diversity can be estimated by quantitative traits using principal component and cluster analysis that can help measure the pattern of genetic diversity in potato germplasm [6-9].

Several genetic diversity studies have been conducted to select genetically distant parents among different crop species on the basis of qualitative and quantitative traits for a hybridization programme [10-12]. In Ethiopia, a number of improved potato varieties have been released by different research Centre and institutions. However, the released varieties have not met the consumer demand for process product making. Therefore, this study was organized to estimate the magnitude of genetic distance (Euclidean distance) and to identify the major traits contributing for processing quality traits among the studied genotypes by using cluster and principal component analysis.

\section{Materials and Methods}

\subsection{Experimental site, materials and design}

The study was conducted at Holleta Agricultural Research Center (HARC), Ethiopia. Holetta Agricultural Research Center is located at $09^{\circ} 00^{\prime} \mathrm{N}, 38^{0} 30^{\prime} \mathrm{E}$ at an altitude of 2,400 m.a.s.l. A total of 24 potato genotypes were used for the experiment. These included 21 genotypes and three released varieties (Table 1). The 24 genotypes were planted at Holetta Agricultural Research Centre experiment station during the main cropping season of 2017. The experiment was laid out in randomized complete block design (RCBD) with three replications and each plot was $3.6 \mathrm{~m}$ (length) x $4.5 \mathrm{~m}$ (width) (16.2 $\mathrm{m}^{2}$ gross plot size) that consisted six rows each containing 12 plants and thus 72 plants per plot in total. The spacing between rows and plants was $0.75 \mathrm{~m}$ and $0.30 \mathrm{~m}$, respectively. The spacing between plots and adjacent replications was $1 \mathrm{~m}$ and $1.5 \mathrm{~m}$, respectively.

Table 1. List of potato genotypes used for this study

\begin{tabular}{cccc}
\hline No. & Accession code & No. & Accession code \\
\hline 1 & CIP-396034.268 & 13 & CIP-394611.112 \\
2 & CIP-393220.54 & 14 & CIP-392617.54 \\
3 & CIP-395017.229 & 15 & CIP-381381.20 \\
4 & CIP-392797.27 & 16 & CIP-398180.289 \\
5 & CIP-395112.19 & 17 & CIP-.398190.89 \\
6 & CIP-399075.7 & 18 & CIP-398190.404 \\
7 & CIP-393280.64 & 19 & CIP-391058.175 \\
8 & CIP-398098.65 & 20 & CIP-396034.103 \\
9 & CIP-393385.39 & 21 & CIP-391046.14 \\
10 & CIP-396027.205 & 22 & Belete (CIP-393371.58) \\
11 & CIP-393077.159 & 23 & Gudanie (CIP-386423.13) \\
12 & CIP-399002.52 & 24 & Dagim (CIP-396004.337) \\
\hline
\end{tabular}

CIP = International Potato Center

\subsection{Data collection}

\subsubsection{Phenology and growth parameters}

Phenology and growth data were recorded as days to $50 \%$ flowering, days to physiological maturity, plant height $(\mathrm{cm})$, average stems number and leaf area index $\left(\mathrm{cm}^{-3}\right)$

\subsubsection{Yield and yield components}

The data collected for yield variables included shoot dry weight (g), tubers dry weight (g), dry total biomass weight (g), number of tubers per hill, average tuber weight (g/tuber), tuber size distribution: small $(<35 \mathrm{~mm})$, medium (35 to $50 \mathrm{~mm}$ ), and large $(>50 \mathrm{~mm})$ as a percent of total harvested tubers, total tuber yield $\left(\mathrm{t} \mathrm{ha}^{-1}\right)$, marketable tuber yield ( $\mathrm{t}$ $\left.\mathrm{ha}^{-1}\right)$ and unmarketable tuber yield $\left(\mathrm{t} \mathrm{ha}^{-1}\right)$.

\subsubsection{Tuber physical and internal quality traits}

Tuber geometric mean diameter $(\mathbf{D g})(\mathbf{m m})$ : Thuber sizes as a geometric mean diameter of ten randomly selected 
tubers were determined by measuring the length (L), width (W) and thickness (T) using digital Vernier calliper with an accuracy of $0.01 \mathrm{~mm}$ from each plot. The geometric mean diameter $\left(\mathrm{D}_{\mathrm{g}}\right)$ was calculated using the cube root of the product of $\mathrm{L}, \mathrm{W}$ and $\mathrm{T}$.

$\mathrm{Dg}=(\mathrm{LWT})^{0.333}$ where: $\mathrm{L}$ is length; $\mathrm{W}$ is width and $\mathrm{T}$ is thickness of the tuber.

Tuber length $(\mathbf{L})$ to width $(\mathbf{W})$ ratio $(\mathbf{L} / \mathbf{W}=\mathbf{R})$ : This was computed as the ratio of tuber length $(\mathrm{L})$ to tuber width (W). R $=\mathrm{L} / \mathrm{W}$

Sphericity of tuber $(\Phi)(\%)$ : Tuber sphericity was determined by using the formula as described by [13] $\Phi=(\mathrm{Dg} / \mathrm{L})$ x 100 where, $\Phi$ is sphercity of the tuber, Dg is geometric mean diameter and L is length.

Surface area (S) $\left(\mathbf{m m}^{2}\right)$ : Tubers surface area was determined according to Baryeh [14].

$\mathrm{S}=\pi \mathrm{Dg}^{2}$ where: $\mathrm{S}$ is surface area and $\mathrm{Dg}$ is geometric mean diameter.

Specific gravity of tubers $(\mathbf{S g})\left(\mathrm{gcm}^{-3}\right)$ : Specific gravity of tubers $(\mathrm{Sg})\left(\mathrm{gcm}^{-3}\right)$ : The specific gravity of tubers was determined using the air and, under water weight method. Five kilograms of fresh tubers of different shapes and sizes were randomly selected from each plot per genotype in a net bag. The tubers were washed with tap water and allowed to dry. The tubers were first weighed in air and then re-weighed after fully immersed in water. The specific gravity of each sample was then determined according to the formula [15].

$$
\text { Specific gravity }=\frac{\text { weight in air }}{\text { weight in air }- \text { weight in water }}
$$

Dry matter content (\%): The total dry matter content (DMC) was calculated according to Porras et al. [16]. Five tubers of each variety were chopped (about $500 \mathrm{~g}$ total) into small 1-2 cm cubes. The cubes were mixed thoroughly and two sub-samples of $200 \mathrm{~g}$ each taken. The exact weight of each sub-sample was recorded as fresh weight. Subsequently, each sub-sample was placed in an oven set at $80^{\circ} \mathrm{C}$ and dried for 48 hours until constant weight. Each sub-sample were weighed immediately and recorded as dry weight. The dry matter content for each sub-sample was then computed.

$$
\text { Dry matter content }(\%)=\frac{\text { dry weight }}{\text { fresh weight }} * 100
$$

Total starch content $(\mathbf{g} / \mathbf{1 0 0 g})$ : The total starch content was estimated from dry matter percent using the following formula.

Starch content $(\%)=17.55+0.891 *$ (tuber dry weight $\%-24.182)$ [17].

\subsection{Data analysis}

\subsubsection{Genetic distance and clustering}

Genetic distance of 24 potato genotypes was estimated using Euclidean distance (ED) calculated from quantitative traits after standardization (subtracting the mean value from each value and dividing it by the standard deviation) as established as follows [18].

$$
\operatorname{EDjk}={\sqrt{\sum_{i=1}^{n}(X i j-X i k)^{2}}}^{2}
$$

Where; EDjk = distance between genotypes $\mathrm{j}$ and $\mathrm{k}$; $\mathrm{xij}$ and $\mathrm{xik}=$ phenotype traits values of the $\mathrm{i}^{\text {th }}$ character for genotypes $\mathrm{j}$ and $\mathrm{k}$, respectively; and $\mathrm{n}=$ number of phenotype traits used to calculate the distance. The distance matrix from phenotype traits was used to construct dendrogram based on the Unweighted Pair-group Method with Arithmetic Means (UPGMA). The results of cluster analysis were presented in the form of dendrogram. In addition, mean ED was calculated for each genotype by averaging of a particular genotype to the other 23 genotypes. The calculated average distance (ED) was used to estimate which genotype(s) is closest or distant to others.

\subsubsection{Principal component analysis}

Principal component analysis (PCA) was computed to find out the characters, which accounted more to the total variation. The data were standardized to mean zero and variance of one before computing principal component analysis. The principal component based on correlation matrix was calculated using SAS software. According to Gutten's lower bound principle that eigenvalues $<1$ should be ignored [19].

\section{Results and Discussion}

\subsection{Genetic Distances among Potato Genotypes}

The genetic distances result of 276 pair of potato genotypes are presented in Table 2. Genetic distances (Euclidean distances) among introduce genotypes were higher than those among the released varieties. This indicated that there is a 
higher chance of improving tuber yield, physical and internal quality traits through selection and hybridization of potato genotypes for yield and processing quality. The highest genetic distances (Euclidean distance) were between CIP396027.205and Belete (10.94) followed by between CIP395017.229 and CIP399002.52 (10.87) and between CIP-398098.65 and CIP-396027.205 (10.62), while the lowest genetic distances (Euclidean distance) were between CIP-398098.65 and CIP394611.112 (2.73) followed by between CIP-391058.175 and Gudaine (2.79) and between CIP395017.229 and CIP392797.27 (2.88) (Table 2). Similar findings were reported by Tesfaye et al. [20] who reported observation of significant genetic distance between released potato varieties. Wassu [21] studied Euclidean distance of all possible pairs of 21 potato genotypes and reported a genetic distance that ranged from 0.71 to 7.23 . Nadeem [22] reported the grouping of 12 genotypes of potato into three major clusters and Euclidian distance for morphological traits that ranged from 1.17 to 7.79 using UPGMA cluster analysis. Panigrahi et al. [23] estimated genetic distances of all possible pairs of 17 potato genotypes and reported a genetic distance ranging from 3.457 to 13.540. Carputo et al. [24] reported significant genetic distance among 12 potato genotypes. Euclidean distance value ranging from 0.24 to 0.72 was reported by Abebe et al. [25] in a phenotypic diversity analysis of 25 potato genotypes. Similar findings were also reported in diversity studies carried by Haydar et al. [10], Datta et al. [26], Rangare and Rangare [27], Arslanoglu et al. [28] who reported wide genetic distance (Euclidean distance) and phylogenetic association among potato genotypes.

Table 2. Euclidean distances of 24 potato genotypes based on 23 quantitative traits evaluated at Holetta in 2017

\begin{tabular}{|c|c|c|c|c|c|c|c|c|c|c|c|c|c|c|c|c|c|c|c|c|c|c|c|}
\hline & 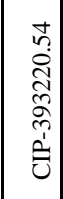 & 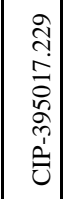 & 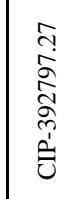 & 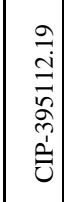 & 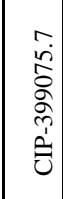 & 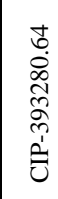 & $\begin{array}{l}\text { Lి } \\
0 \\
0 \\
0 \\
0 \\
0 \\
0 \\
0 \\
0\end{array}$ & 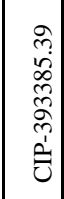 & 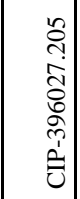 & 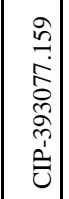 & 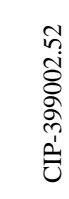 & 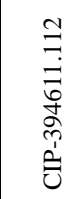 & 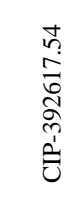 & 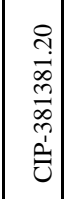 & 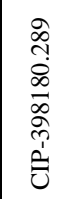 & 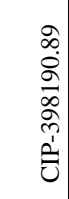 & 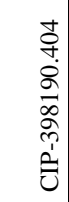 & 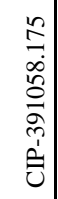 & 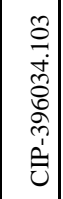 & 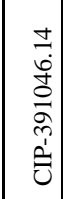 & 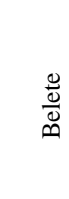 & 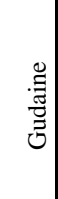 & 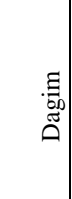 \\
\hline CIP396034.268 & 6.13 & 5.35 & 4.27 & 3.62 & 7.37 & 3.17 & 5.41 & 7.71 & 7.92 & 4.82 & 8.31 & 5.39 & 4.79 & 4.18 & 4.64 & 4.80 & 4.10 & 4.92 & 5.56 & 6.59 & 5.56 & 5.92 & 6.81 \\
\hline CIP393220.54 & & \begin{tabular}{|l|}
6.54 \\
\end{tabular} & 5.56 & 6.34 & 6.95 & 6.49 & 7.95 & 5.49 & \begin{tabular}{|l|}
5.56 \\
\end{tabular} & \begin{tabular}{|l|}
3.87 \\
\end{tabular} & \begin{tabular}{|l|l|}
9.07 \\
\end{tabular} & \begin{tabular}{|l|}
8.01 \\
\end{tabular} & 8.11 & 5.73 & 5.89 & 6.95 & 6.48 & 3.28 & \begin{tabular}{|l|}
5.24 \\
\end{tabular} & 3.12 & 8.33 & 3.98 & 4.75 \\
\hline CIP395017.229 & & & 2.88 & 4.82 & 7.19 & 6.64 & 8.51 & 7.99 & 6.83 & 5.73 & 10.87 & 8.68 & 6.13 & 6.06 & 6.56 & 5.53 & 6.18 & 6.04 & 7.80 & 6.36 & 7.81 & 6.78 & 6.07 \\
\hline CIP39 & & & & 4.41 & 6.65 & 5.88 & 7.20 & 7.49 & \begin{tabular}{|l|}
7.16 \\
\end{tabular} & 5.40 & 10.47 & 7.24 & 5.02 & 4.98 & 5.17 & 4.33 & 4.95 & 4.43 & \begin{tabular}{|l|}
6.98 \\
\end{tabular} & 5.20 & 6.33 & 5.38 & 5.74 \\
\hline 12.19 & & & & & 8.84 & 5.45 & 6.72 & 7.81 & \begin{tabular}{|l|}
7.82 \\
\end{tabular} & 5.45 & 10.56 & \begin{tabular}{|l|l|}
7.41 \\
\end{tabular} & 5.24 & 5.38 & 5.45 & 4.92 & 5.03 & 6.33 & 6.01 & 7.59 & 7.35 & 6.66 & 6.85 \\
\hline CIP399075.7 & & & & & & 7.77 & 8.96 & 8.81 & \begin{tabular}{|l|}
8.26 \\
\end{tabular} & 6.94 & 8.58 & 8.96 & 9.06 & 7.26 & 8.35 & 7.56 & 8.85 & 6.09 & 9.75 & 6.63 & 9.01 & 5.69 & 7.68 \\
\hline CIP393280.64 & & & & & & & 5.07 & 7.04 & 7.91 & 4.75 & 6.53 & \begin{tabular}{|l|}
5.14 \\
\end{tabular} & 5.41 & 3.57 & 4.98 & 6.04 & 4.72 & 4.91 & 5.16 & 6.85 & 5.21 & 5.66 & 7.08 \\
\hline CIP398098.65 & & & & & & & & 7.96 & 10.62 & 7.48 & \begin{tabular}{|l|l|}
8.54 \\
\end{tabular} & 2.73 & 5.15 & 4.68 & 5.22 & 4.96 & 5.27 & 6.22 & 7.26 & 8.74 & 4.28 & 6.14 & 9.82 \\
\hline CIP393385.39 & & & & & & & & & \begin{tabular}{|l|}
5.38 \\
\end{tabular} & 4.42 & 8.82 & 8.61 & 9.40 & 6.40 & 7.29 & 8.63 & 8.36 & 5.71 & 6.83 & 6.93 & 8.65 & 5.77 & 7.37 \\
\hline CIP396027.205 & & & & & & & & & & 4.38 & 9.55 & 10.58 & 10.68 & 7.67 & 7.92 & 9.35 & 9.77 & 6.60 & 8.02 & 6.25 & 10.94 & 7.05 & 5.24 \\
\hline CIP393077.159 & & & & & & & & & & & 7.06 & 7.82 & 7.68 & 5.40 & 5.83 & 7.04 & 6.54 & 4.23 & 5.06 & 5.06 & 7.85 & 5.08 & 5.18 \\
\hline CIP399002.52 & & & & & & & & & & & & 8.51 & 10.48 & 8.42 & 8.87 & 10.25 & 10.02 & 8.19 & 9.16 & 9.41 & 9.48 & 8.59 & 10.27 \\
\hline CIP394611.112 & & & & & & & & & & & & & 5.74 & 4.26 & 4.98 & 5.73 & 5.78 & 6.01 & 7.52 & 8.39 & 3.94 & 6.43 & 9.80 \\
\hline CIP392617.54 & & & & & & & & & & & & & & 5.04 & 5.69 & 4.05 & 3.75 & 6.35 & \begin{tabular}{|l|l}
7.68 \\
\end{tabular} & 8.14 & 4.00 & 7.14 & 8.96 \\
\hline CIP381381.20 & & & & & & & & & & & & & & & 4.30 & 5.19 & 5.11 & 3.86 & \begin{tabular}{|l|l|}
5.96 \\
\end{tabular} & 6.24 & 4.36 & 4.21 & 6.85 \\
\hline CIP398180.289 & & & & & & & & & & & & & & & & 4.20 & 5.63 & 4.61 & 6.44 & 6.19 & 6.33 & 5.60 & 6.16 \\
\hline $\begin{array}{l}\text { CIP398190.89 } \\
\end{array}$ & & & & & & & & & & & & & & & & & 4.77 & 5.55 & 7.95 & 7.08 & 6.08 & 5.72 & 7.59 \\
\hline CIP398190.404 & & & & & & & & & & & & & & & & & & 5.24 & 5.44 & 6.64 & 4.72 & 6.07 & 7.95 \\
\hline CIP391058.175 & & & & & & & & & & & & & & & & & & & \begin{tabular}{|l|}
5.39 \\
\end{tabular} & 2.84 & 5.90 & 2.79 & 5.08 \\
\hline CIP396034.103 & & & & & & & & & & & & & & & & & & & & 6.33 & 7.66 & 6.02 & 6.45 \\
\hline CIP391046.14 & & & & & & & & & & & & & & & & & & & & & 8.23 & 4.49 & 4.29 \\
\hline Belete & & & & & & & & & & & & & & & & & & & & & & 6.69 & 9.97 \\
\hline Gudaine & & & & & & & & & & & & & & & & & & & & & & & 5.92 \\
\hline
\end{tabular}

CIP = International Potato Center

\subsection{Cluster Analysis}

Cluster analysis for processing quality traits among the potato genotypes was assessed by the unweighted Pair Group Method with an Arithmetic average (UPGMA). The Euclidean distance matrix of 276 pair of genotypes estimated from quantitative tuber quality, yield and yield related traits was used to construct dendrograms based on the Unweighted Pair-group methods with Arithmetic Means (UPGMA). Based on the results of the cluster analysis 24 potato genotypes were divided into six cluster, in terms of 23 quantitative traits (Figure 1). This grouping was done on the basis of quantitative traits. Cluster II contained eight (33.33\%) potato genotypes, cluster I had seven genotypes (29.17\%). cluster III had four (16.67\%) genotypes, cluster IV had three (12.50\%) potato genotypes and also cluster V and VI contained each one (4.17\%) genotype. The three commercial varieties fall in cluster II and cluster III. Generally, in cluster II and cluster VI observed best genotypes for yield and processing quality traits and also could be selected as parents for future crossing program. A similar trend in cluster analysis among potato genotypes has also been suggested by Haydar et al. [10] thirty potato genotypes into six clusters; Tesfaye et al. [20] twenty five potato varieties into five clusters and Rangare and Rangare [27] also reported that potato genotype clusters constructed and that had higher mean values for de- 
sirable traits including tuber yield and quality traits. Arslanoglu et al. [28] reported the grouping of 146 local potato genotypes collected from the Eastern Black Sea region of Turkey and into 27 clusters that had higher mean values for desirable morphological traits.

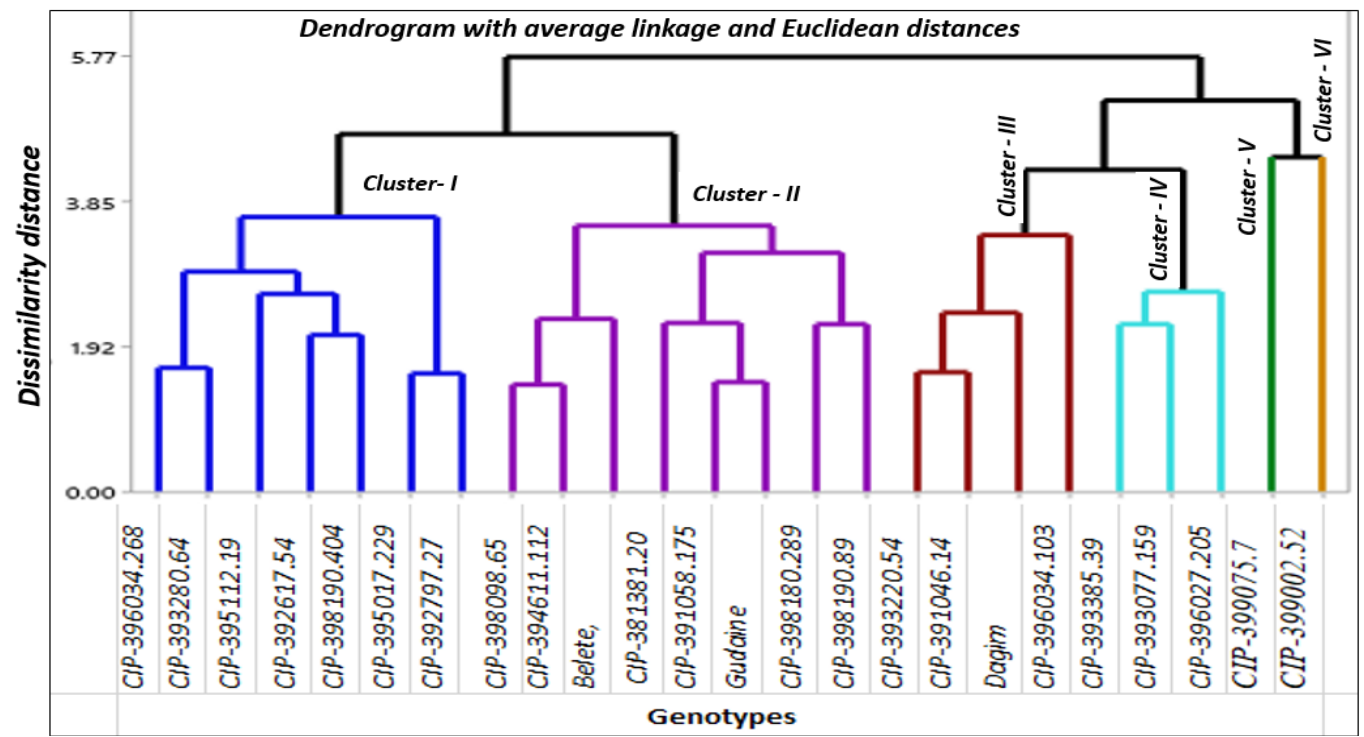

Figure 1. Dendrogram of 24 potato genotypes by Unweighted Pair group Method with Arithmetic Means (UPGMA) clustering method from Euclidean distances matrix estimated from 23 quantitative traits.

\subsection{Cluster mean for characters}

According to the cluster mean analysis, genotypes in Cluster I are characterized by high average tuber weight (78.12g), large size tubers (36.85\%), geometric mean diameter $\left(58.47 \mathrm{~mm}^{3}\right)$ and surface area $\left(10,771.00 \mathrm{~mm}^{2}\right)$ (Table 3). Genotypes in Cluster II had long flower days (58.70), leaf area index $\left(2.85 \mathrm{~cm}^{-3}\right)$, tubers dry mass weight $(904.71$ g/plant), total biomass weight (1,156.28 g/plant), total tuber yield (35.31 t ha $\left.{ }^{-1}\right)$, marketable tuber yield (31.38 $\left.\mathrm{t} \mathrm{ha}^{-1}\right)$ and unmarketable tuber yield $\left(3.92 \mathrm{t} \mathrm{ha}^{-1}\right)$. Genotypes grouped under Cluster III showed early maturity (89.17 days), highest medium tuber size (47.36\%) and lowest unmarketable tuber yield $\left(1.90 \mathrm{t} \mathrm{ha}^{-1}\right)$. The highest average stems number (5.29) and sphericity of the tuber (92.17\%) were observed under cluster IV. Cluster V genotype and had medium maturity (106 days) and high length width ratio (1.87). Genotypes in Cluster VI showed medium maturity (106.00 days), plant height $(122.70 \mathrm{~cm})$, shoot dry mass weight (439.00 g/plant), average tuber number per hill (15.06), small size tubers (56.67\%), specific gravity of tubers $\left(1.10 \mathrm{~g} \mathrm{~cm}^{-3}\right)$, dry matter content (25.75\%), total starch content (18.95 g/100 g). Generally, genotypes that fall under cluster II were found to be important for highest total tuber yield and marketable tuber yield, while those in cluster III for early maturity and high percent of medium size tuber and those in cluster VI for what traits? To obtain genotypes with highest specific gravity of tuber, dry mater content and total starch content for processing quality traits. It could be concluded that cluster II and cluster VI were best for tuber yield and processing quality traits and could be selected as parents for crossing program. Similar reports were made in a cluster analysis by Haydar et al. [10], Datta et al [26], Dangi et al. [29]..

\subsection{Principal component analysis}

Principal component analysis with eigenvalues $>1$ contributing $88.20 \%$ of total Cumulative variances among 24 potato genotypes for the 23 quantitative (Table 4). According to eigenvector analysis, the observed variation for first, second, third, fourth, fifth and sixth principal component were about $34.3 \%, 20.7 \%, 12,9 \%, 6.9 \%$ and 5.3\%, respectively. In the first principal component analysis, days to maturity $(0.22)$, leaf area index $\left(0.28 \mathrm{~cm}^{-3}\right)$, average tuber weight $(0.25 \mathrm{~g} /$ tuber $)$, total biomass weight $(0.26 \mathrm{~g} /$ plant $)$, total tuber yield $\left(0.32 \mathrm{t} \mathrm{ha}^{-1}\right)$, marketable tuber yield $(0.31 \mathrm{t}$ $\left.\mathrm{ha}^{-1}\right)$, geometric mean diameter $\left(0.26 \mathrm{~mm}^{3}\right)$ and surface area $\left(0.26 \mathrm{~mm}^{2}\right)$ were the most contributing traits for yield. The yield components plant height $(0.34 \mathrm{~cm})$ shoot dry mass weight $(0.31 \mathrm{~g} / \mathrm{plant})$, average tuber number per hill $(0.32)$, small size tubers $(0.29 \%)$ and processing quality traits specific gravity of tubers $\left(0.30 \mathrm{~g} \mathrm{~cm}^{-3}\right)$, dry matter content $(0.30 \%)$,total starch content $(0.30 \mathrm{~g} / 100 \mathrm{~g})$ were the principal traits of second principal component. The principal component analysis (PCA) indicated that PC1 and PC2 for yield, yield components and quality traits related to processing were positive. Such results indicated that those characters contributed maximum towards diversity. A similar trend in principal component analysis among potato genotypes has also been suggested by; Latifeh and Davoud [30] in potato genotypes reported greater eigenvector values for tuber yield and tuber uniformity traits in the first and/or second prin- 
cipal components. Khlestkin et al. [31] reported that for the set of 90 potato varieties, a total of 23 principal components contributed more than $1 \%$ of common genotype variance. The first three components described $31.8 \%$ of variance. Rymuza [32] reported that the principal component analysis on early maturing potato quality was associated with the first six components: PC1, PC2, PC3, PC4, PC5 and PC6. The components explained over $78.34 \%$ of the total variance that is overall multi-dimensional variation of traits.

Table 3. Mean values of six clusters for 23 quantitative traits of 24 potato genotypes evaluated at Holetta in 2017

\begin{tabular}{|c|c|c|c|c|c|c|}
\hline \multirow{2}{*}{ Quantitative traits } & \multicolumn{6}{|c|}{ Cluster } \\
\hline & $\mathbf{I}$ & II & III & IV & $\mathbf{V}$ & VI \\
\hline Days to $50 \%$ flowering & 51.05 & 58.70 & 51.50 & 54.44 & 55.33 & 49.00 \\
\hline Days to maturity & 97.14 & 97.71 & 89.17 & 90.56 & 106.00 & 106.00 \\
\hline Plant height (cm) & 78.28 & 77.08 & 72.32 & 83.59 & 104.13 & 122.70 \\
\hline Average stems number & 3.73 & 3.78 & 4.62 & 5.29 & 3.13 & 3.37 \\
\hline Leaf area index & 2.69 & 2.85 & 2.14 & 2.17 & 2.39 & 2.33 \\
\hline Shoot dry mass weight (g/plant) & 228.86 & 251.58 & 149.59 & 211.22 & 234.67 & 439.00 \\
\hline Tubers dry mass weight (g/plant) & 824.10 & 904.71 & 847.83 & 742.78 & 595.67 & 715.00 \\
\hline Total biomass weight (g/plant) & $1,052.94$ & $1,156.28$ & 997.43 & 954.00 & 830.30 & $1,154.00$ \\
\hline Average tuber number per hill & 9.68 & 11.20 & 9.55 & 14.35 & 12.27 & 15.06 \\
\hline Average tuber weight (g/tuber) & 78.12 & 71.51 & 63.01 & 44.38 & 47.71 & 40.75 \\
\hline Total tuber yield (t/ha) & 33.51 & 35.31 & 26.43 & 27.79 & 25.69 & 27.27 \\
\hline Marketable tuber yield (t/ha) & 31.13 & 31.38 & 24.53 & 25.16 & 23.54 & 23.58 \\
\hline Unmarketable tuber yield (t/ha) & 2.38 & 3.92 & 1.90 & 2.64 & 2.16 & 3.69 \\
\hline Small size tubers (\%) & 27.48 & 33.13 & 32.13 & 43.15 & 46.89 & 56.67 \\
\hline Medium size tubers (\%) & 35.67 & 39.74 & 47.36 & 41.61 & 42.13 & 34.38 \\
\hline Large size tubers (\%) & 36.85 & 27.13 & 20.52 & 15.24 & 10.98 & 8.95 \\
\hline Geometric mean diameter $\left(\mathrm{mm}^{3}\right)$ & 58.47 & 56.91 & 51.60 & 52.01 & 57.21 & 50.24 \\
\hline Sphericity of the tuber (\%) & 81.85 & 76.51 & 79.51 & 92.17 & 61.98 & 83.33 \\
\hline Surface area $\left(\mathrm{mm}^{2}\right)$ & $10,771.00$ & $10,221.50$ & $8,412.00$ & $8,502.67$ & $10,287.00$ & $7,933.00$ \\
\hline Length to width ratio & 1.21 & 1.35 & 1.29 & 1.03 & 1.87 & 1.20 \\
\hline Specific gravity of tubers $\left(\mathrm{g} / \mathrm{cm}^{3}\right)$ & 1.083 & 1.090 & 1.085 & 1.078 & 1.078 & 1.103 \\
\hline Dry matter content (\%) & 21.37 & 22.87 & 21.79 & 20.28 & 20.25 & 25.75 \\
\hline Total starch content (g/100g) & 15.04 & 16.38 & 15.42 & 14.07 & 14.05 & 18.95 \\
\hline
\end{tabular}

$\mathrm{cm}=$ centimeter, $\mathrm{g}=$ gram, $\mathrm{t} / \mathrm{ha}=$ ton per hectare, $\mathrm{mm}^{3}=$ millimeter cub, $\mathrm{mm}^{2}=$ millimeter square and $\mathrm{g} / \mathrm{cm}^{3}=$ gram per centimeter cub

Table 4. Eigenvalue, percentage and cumulative variances of the first eight principal components (PC) for 23 quantitative and six qualitative traits in 24 potato genotypes

\begin{tabular}{|c|c|c|c|c|c|c|}
\hline Characters & PC1 & PC2 & PC3 & PC4 & PC5 & PC6 \\
\hline Days to $50 \%$ flowering & 0.07 & 0.09 & -0.10 & 0.30 & -0.46 & 0.33 \\
\hline Days to maturity & 0.22 & 0.20 & -0.21 & -0.25 & 0.01 & -0.06 \\
\hline Plant height (cm) & 0.00 & 0.34 & -0.16 & -0.29 & 0.09 & -0.24 \\
\hline Average stems number & -0.22 & 0.04 & 0.36 & 0.05 & -0.19 & -0.05 \\
\hline Leaf area index & 0.28 & -0.04 & -0.08 & 0.01 & -0.16 & -0.06 \\
\hline Shoot dry mass weight (g/plant) & 0.16 & 0.31 & -0.14 & -0.20 & -0.01 & -0.18 \\
\hline Tubers dry mass weight (g/plant) & 0.22 & 0.01 & 0.19 & 0.36 & 0.02 & -0.21 \\
\hline Total biomass weight (g/plant) & 0.26 & 0.16 & 0.09 & 0.21 & 0.01 & -0.26 \\
\hline Average tuber number per hill & -0.03 & 0.32 & 0.00 & 0.03 & -0.43 & -0.26 \\
\hline Average tuber weight (g/tuber) & 0.25 & -0.26 & 0.11 & -0.01 & 0.18 & 0.18 \\
\hline
\end{tabular}




\begin{tabular}{ccccccc}
\hline Total tuber yield (t/ha) & 0.32 & 0.00 & 0.12 & 0.08 & -0.18 & -0.06 \\
Marketable tuber yield (t/ha) & 0.31 & -0.02 & 0.15 & 0.07 & -0.11 & -0.19 \\
Unmarketable tuber yield (t/ha) & 0.17 & 0.08 & -0.07 & 0.05 & -0.37 & 0.52 \\
Small size tubers (\%) & -0.18 & 0.29 & -0.24 & -0.06 & -0.10 & 0.10 \\
Medium size tubers (\%) & -0.16 & 0.05 & 0.12 & 0.49 & 0.06 & -0.27 \\
Large size tubers (\%) & 0.24 & -0.28 & 0.14 & -0.22 & 0.05 & 0.06 \\
Geometric mean diameter (mm ${ }^{3}$ ) & 0.26 & -0.21 & -0.16 & -0.11 & -0.14 & -0.17 \\
Sphericity of the tuber (\%) & -0.08 & 0.06 & 0.46 & -0.33 & -0.24 & -0.03 \\
Surface area (mm $\left.{ }^{2}\right)$ & 0.26 & -0.22 & -0.16 & -0.11 & -0.14 & -0.17 \\
Length to width ratio & 0.03 & -0.03 & -0.50 & 0.33 & 0.16 & -0.01 \\
Specific gravity of tubers (g/cm $\left.{ }^{3}\right)$ & 0.21 & 0.30 & 0.15 & 0.05 & 0.25 & 0.19 \\
Dry matter content (\%) & 0.20 & 0.30 & 0.15 & 0.05 & 0.25 & 0.20 \\
Total starch content (g/100g) & 0.20 & 0.30 & 0.15 & 0.05 & 0.24 & 0.20 \\
\hline Eigenvalue & 7.88 & 4.77 & 2.76 & 2.07 & 1.58 & 1.22 \\
Variances (\%) & 34.30 & 20.70 & 12.00 & 9.00 & 6.90 & 5.30 \\
Cumulative variances (\%) & 34.30 & 55.00 & 67.00 & 76.00 & 82.90 & 88.20 \\
\hline
\end{tabular}

$\mathrm{cm}=$ centimeter, $\mathrm{g}=$ gram, $\mathrm{t} / \mathrm{ha}=$ ton per hectare, $\mathrm{mm}^{3}=$ millimeter cub, $\mathrm{mm}^{2}=$ millimeter square and $\mathrm{g} / \mathrm{cm}^{3}=$ gram per centimeter cub

\section{Conclusion}

The research results indicated the presence of wide genetic variations among potato genotypes for tuber yield, internal and external tuber quality for most of the traits. The principal component analysis showed that the first eight principal components accounted for $88.20 \%$ among 24 potato genotypes for the twenty-three traits. The genetic distances among the 24 potato genotypes ranged from 2.73 to 10.94 and the genotypes were grouped into six clusters based on quantitative traits. Cluster II contained eight (33.33\%) potato genotypes, cluster I had seven genotypes (29.17\%). cluster III had four (16.67\%) genotypes, cluster IV had three (12.50\%) potato genotypes and also cluster V and VI contained each one (4.17\%) genotype. The three commercial varieties fall in cluster II and cluster III. Analysis of the cluster mean for characters revealed the possibility of obtaining or developing varieties with highest total tuber yield, marketable tuber yield, specific gravity, dry mater content and total starch content with other desirable traits for processing purpose and tuber yield through selection of genotypes in cluster II and VI.

\section{Acknowledgement}

I am grateful to the Ethiopian Institute Agricultural Research (EIAR) and Holetta Agricultural Research Centre (HARC) for fanatical support and providing all necessary facilities.

\section{References}

[1] Birch, P. R., Bryan, G., Fenton, B., Gilroy, E. M., Hein, I., Jones, J. T., Prashar, A., Taylor, M. A., Torrance, L., and Toth, I. K. (2012). Crops that feed the world 8: Potato: are the trends of increased global production sustainable?. Food Security, 4(4): 477-508.

[2] Hancock, R. D., Morris, W. L., Ducreux, L. J., Morris, J. A., Usman, M., Verrall, S. R., Fuller, J., Simpson, C. G., Zhang, R., Hedley, P. E., and Taylor, M. A. (2014). Physiological, biochemical and molecular responses of the potato (Solanum tuberosum L.) plant to moderately elevated temperature. Plant Cell and Environment, 37(2): 439-450.

[3] Huamán, Z. and Spooner, D. M. (2002). Reclassification of landrace populations of cultivated potatoes (Solanumsect. Petota). American Journal of Botany, 89(6): 947-965.

[4] Ali, Y., Atta, B. M., Akhter, J., Monneveux, P., and Lateef, Z. (2008). Genetic variability, association and diversity studies in wheat (Triticum aestivum L.) germplasm. Pakistan Journal of Biotechnology, 40(5): 2087-2097.

[5] Bhandari, H. R., Bhanu, A. N., Srivastava, K., Singh, M. N., and Shreya, I. (2017). Assessment of Genetic Diversity in Crop Plants: An Overview. Advance Plants Agricultural Research, 7(3): 00255.

[6] Akkale, C., Yildirim, Z., Yildirim, M. B., Canan, K. A. Y. A., Ozturk, G., and Tanyolac, B. (2010). Assessing genetic diversity of some potato (Solanum tuberosum L.) genotypes grown in Turkey using the AFLP marker technique. Turkish Journal of 
Field Crops, 15(1), 73-78.

[7] Das, A. B., Mohanty, I. C., Mahapatra, D., Mohanty, S., and Ray, A. (2010). Genetic variation of Indian potato (Solanum tuberosum L.) genotypes using chromosomal and RAPD markers. Crop Breeding and Applied Biotechnology, 10(3), $238-246$.

[8] Khan, M. F., Tabassum, N., Latif, A., Khaliq, A., and Malik, M. (2013). Morphological characterization of potato (Solanum tuberosum L.) germplasm under rainfed environment. African Journal of Biotechnology, 12(21): 3214-3223.

[9] Salimi, H., Bahar, M., Mirlohi, A., and Talebi, M. (2016). Assessment of the genetic diversity among potato cultivars from different geographical areas using the genomic and EST microsatellites. Iranian Journal of Biotechnology, 14(4), 270.

[10] Haydar, A., Ahmed, M. B., Hannan, M. M., Razvy, M. A., Mandal, M. A., Salahin, M., Karim, R., and Hossain, M. (2007). Analysis of genetic diversity in some potato varieties grown in Bangladesh. Middle-East Journal of Scientific Research, 2(3-4): 143-145.

[11] Ahmadizadeh, M., Shahbazi, H., Valizadeh, M., and Zaefizadeh, M. (2011). Genetic diversity of durum wheat landraces using multivariate analysis under normal irrigation and drought stress conditions. African Journal of Agricultural Research, 6(10): 2294-2302.

[12] Hailegiorgis, D., Mesfin, M., and Genet, T. (2011). Genetic divergence analysis on some bread wheat genotypes grown in Ethiopia. Journal of Central European Agriculture, 12(2): 344-352.

[13] Bayram, M. (2005). Determination of the sphericity of granular food materials. Journal of food engineering, 68(3): 385-390.

[14] Baryeh, E. A. (2001). Physical properties of bambara groundnuts. Journal of Food Engineering, 47(4): 321-326.

[15] Kleinkopf, G. E., Westermann, D. T., Wille, M. J., and Kleinschmidt, G. D. (1987). Specific gravity of Russet Burbank potatoes. American Potato Journal, 64(11): 579-587.

[16] Porras, E., Burgos, G., Sosa, P., and Felde, T. Z. (2014). Procedures for sampling and sample preparation of sweetpotato roots and potato tubers for mineral analysis. Lima, Peru. International Potato Center (CIP), Global Program Genetics and Crop Improvement.

[17] Hassell, R. L., Kelly, D. M., Wittmeyer, E. C., Wallace, C., Grassbaugh, E. M., Elliott, J. Y., and Wenneker, G. L. (1997). Ohio Potato Cultivar Trials. Ohio State University Horticulture Series.

[18] Sneath, P. H. and Sokal, R. R. (1973). Numerical Taxonomy. Freeman and Company, San Francisco, USA.

[19] Kumar, V., Kato, N., Urabe, Y., Takahashi, A., Muroyama, R., Hosono, N., and Matsuda, K. (2011). Genome-wide association study identifies a susceptibility locus for HCV-induced hepatocellular carcinoma. Nature Genetics, 43(5), 455-458.

[20] Tesfaye, A., Shermarland, W., and Thunya, T. (2013). Analysis of the phenotypic diversity within cultivated potato varieties in Ethiopia at three locations. Agriculture and Natural Resources, 47(6): 803-817.

[21] Mohammed, W. (2014). Genetic variability in potato (Solanum tuberosum L.) genotypes for late blight [Phytophthora infestans (Mont.) de Bary] resistance and yield at Haramaya, Eastern Ethiopia. East African Journal of Sciences, 8(1): 13-28.

[22] Iqbal, N., Erum, S., Azim, R., Shakil, M., and Khan, M. F. (2018). Estimation of phenotypic diversity among locally available potato germplasm. International Journal of Biosciences, 13(1), 10-17.

[23] Panigrahi, K. K., Sarkar, K. K., Baisakh, B., and Mohanty, A. (2014). Assessment of genetic divergence in potato (Solanum tuberosum L.) genotypes for yield and yield attributing traits. International Journal of Agriculture, Environment and Biotechnology, 7(2): 247-254.

[24] Carputo, D., Alioto, D., Aversano, R., Garramone, R., Miraglia, V., Villano, C., and Frusciante, L. (2013). Genetic diversity among potato species as revealed by phenotypic resistances and SSR markers. Plant Genetic Resources, 11(2), 131-139.

[25] Abebe, G. K., Bijman, J., Pascucci, S., and Omta, O. (2013). Adoption of improved potato varieties in Ethiopia: The role of agricultural knowledge and innovation system and smallholder farmers' quality assessment. Agricultural Systems, 122: 22-32.

[26] Datta, S., Das, R., and Singh, D. (2015). Evaluation of genetic diversity for yield and quality parameters of different potato (Solanum tuberosum L.) germplasm. Journal of Applied and Natural Science, 7(1): 235-241.

[27] Rangare, S. B. and Rangare, N. R. (2017). Classificatory analysis of potato (Solanum tuberosum L.) Genotypes for yield and yield attributing traits. The Pharma Innovation, 6(9): 94-102.

[28] Arslanoglu, F., Aytac, S., and Oner, K. (2011). Morphological characterization of the local potato (Solanum tuberosum L.) genotypes collected from the Eastern Black Sea region of Turkey. African Journal of Biotechnology, 10(6): 922-932.

[29] Dangi, R., Kumar, A., and Khar, A. (2018). Genetic variability, heritability, and diversity analysis studies in short day tropical onion (Allium cepa L.). Indian Journal of Agricultural Sciences, 88: 948-957.

[30] Nickmanesh, L. and Hassanpanah, D. (2014). Evaluation of genetic diversity for agronomic traits in 127 potato hybrids with using multivariate statistical methods. Indian Journal of Fundamental and Applied Life Sciences, 4(2): 502-507.

[31] Khlestkin, V. K., Rozanova, I. V., Efimov, V. M., and Khlestkina, E. K. (2019). Starch phosphorylation associated SNPs found by genome-wide association studies in the potato (Solanum tuberosum L.). BMC Genetics, 20(1), p. 29.

[32] Rymuza, K. (2015). Multi-trait evaluation of value for cultivation and use of early maturing edible potato cultivars registered in Poland. Journal of Ecological Engineering, 16(1): 50-56. 